\title{
KARAKTERISTIK FISIS AIR LAUT DAN DINAMIKA PERAIRAN KEPULAUAN SERIBU
}

\section{PHYSICAL CHARACTERISTICS OF SEA WATER AND THE DYNAMICS OF A SERIBU ISLAND}

Eva Mustikasari, Agustin Rustam, Hadiwijaya Lesmana Salim, Dwi Yoga Nugroho, Aida Heriati, Utami R. Kadarwati

\author{
Pusat Riset Kelautan, Badan Riset dan SDM, Kementerian Kelautan dan Perikanan \\ Gedung II BRSDM KP lantai 4, Jalan Pasir Putih 2, Ancol Timur, Jakarta Utara \\ e-mail : eva.mustikasari@gmail.com
}

Diterima tanggal: 14 Juni 2019 ; diterima setelah perbaikan: 02 Agustus 2019 ; Disetujui tanggal: 15 November 2019

\begin{abstract}
ABSTRAK
Secara georgrafis perairan Kepulauan Seribu memiliki peran penting dan signifikan terhadap pertumbuhan ekonimi daerah melalui pengembangan industri kelautan seperti jasa perhubungan laut, transhipment, penambangan minyak dan pariwisata. Salah satu unsur penunjang pengembangan Kepulauan Seribu yaitu dengan mengkaji dan menganalisis karakteristik fisis air laut dan dinamika perairannya. Karakteristik fisis dan dinamis air laut seperti temperatur, intensitas cahaya, pasang surut dan arus dikaji dalam penelitian ini bertujuan agar setiap pengembangan memiliki rencana yang baik dan benar karena kondisi perairannya terukur. Metoda utama yang digunakan dalam kajian ini adalah metoda pengukuran in situ serta pemodelan hidrodinamika yang diselesaikan secara numerik. Hasil kajian menunjukkan bahwa Temperatur rata-rata perairan di Kepulauan seribu mencapai $28.582 \mathrm{oC}$ sampai $30,252^{\circ} \mathrm{C}$, sementara nilai intensitas cahaya rata-rata mencapai $0,801 \mathrm{Cd}$ sampai 120,869 Cd. Tipe pasang surut di Kepulauan Seribu merupakan tipe pasang surut Campuran condong harian tunggal. Rms error hasil pengukuran elevasi pasut in situ dan simulasi numerik menunjukkan nilai 0.01564. Kecepatan arus maksimum 0,164 m/det. sedangkan kecepatan arus minimum berkisar 0,002 m/det. Kepulauan seribu merupakan wilayah perairan yang subur dan potensial untuk tumbuh kembang aneka ragam hayati laut.
\end{abstract}

Kata kunci: karakteristik fisis dan dinamika perairan,model numerik hidrodinamika, simulasi numerik.

\section{ABSTRACT}

Geographically, Seribu Islands area has an important and significant role in regional economy growth through the development of marine industry for instance sea transportation services, transhipment, oil mining and tourism. One of the supporting elements in Seribu Islands development is by analyzing the physical characteristics of sea water and its dynamic. This paper examines the sea water physical and dynamic characteristics such as temperature, light intensity, tides and currents to be used in the island development for a comprehensive planning. Main method used in this study is in situ measurement and numerical hydrodynamic modeling. The results of the study showed that the average of temperature is in the range of $28.582^{\circ} \mathrm{C}-30.252^{\circ} \mathrm{C}$ within average of light intensity is between $0.801 \mathrm{Cd}$ and $120.869 \mathrm{Cd}$. The islands have mixed tide prevailing diurnal type. Rms error result from in situ tidal elevation and numerical simulation is 0.01564 . Current speed is varied from $0.002 \mathrm{~m} / \mathrm{s}$ to $0.164 \mathrm{~m} / \mathrm{s}$. Seribu islands are euthropic area and potential for the growth of marine biodiversity.

Keywords: physical characteristics, numerical hydrodynamic modeling, numerical simulation. 


\section{PENDAHULUAN}

Kepulauan Seribu yang terletak di Laut Jawa dan Teluk Jakarta merupakan suatu wilayah dengan karakteristik dan potensi alam yang berbeda dengan wilayah DKI Jakarta lainnya. Secara georgrafis perairan Kepulauan Seribu memiliki peran penting dan signifikan terhadap pertumbuhan ekonimi daerah melalui pengembangan industri kelautan seperti jasa perhubungan laut, transhipment, penambangan minyak dan pariwisata (Suhendar I Sachoemar, 2008). Kepulauan Seribu dengan posisi memanjang dari Utara ke Selatan yang ditandai dengan pulau-pulau kecil berpasir putih dan gosong-gosong karang, pada dasarnya merupakan gugusan pulau-pulau terumbu karang yang terbentuk dan dibentuk oleh biota koral dan biota asosiasinya (algae, moluska, foraminifera dan lain-lain) dengan bantuan proses dinamika alam. Sesuai dengan karakteristik tersebut dan kebijaksanaan pembangunan DKI Jakarta, maka pengembangan wilayah kepulauan seribu diarahkan untuk: Meningkatkan kegiatan pariwisata, meningkatkan kualitas kehidupan masyarakat nelayan melalui peningkatan budidaya laut, pemanfaatan sumber daya perikanan dengan konservasi ekosistem terumbu karang dan mangrove. Salah satu unsur penunjang pengembangan Kepulauan Seribu tersebut yaitu dengan mengkaji dan menganalisis fenomena fisis dan dinamis air laut yang juga dapat diaplikasikan ke bidang-bidang lainnya seperti rekayasa, lingkungan, perikanan, bencana laut dan mitigasi (pengelolaan dan pencegahan). Fenomena fisis dan dinamis air laut seperti temperatur, intensitas cahaya, pasang surut dan arus dikaji dalam penelitian ini dengan tujuan agar setiap pengembangan memiliki rencana yang baik dan benar karena kondisi perairannya terukur (Dahuri et al., 2013). Metoda utama yang digunakan dalam kajian ini adalah pemodelan hidrodinamika yang diselesaikan secara numerik. Hal ini didukung oleh semakin pesatnya perkembangan dalam bidang teknologi komputasi dan solusi dari metoda numerik, sehingga menjadikan simulasi numerik sebagai salah satu cara yang efektif dan efisien. Sudah ada beberapa kajian sebelumnya seperti: Pranowo et al. (2015), Arifin et al. (2015), Rustam (2011), namun umumnya kajian kajian tersebut fokus di Kepulauan sisi Selatan yang menjadi bagian dari Teluk jakarta. Belum banyak kajian untuk Kepulauan Seribu secara utuh sehingga perlu adanya pemuktahiran Informasi. Hasil kajian ini diharapkan dapat digunakan sebagai referensi dalam pengembangan kawasan Kepulauan Seribu.

\section{BAHAN DAN METODE}

Metode yang digunakan dalam kajian ini adalah sebagai berikut:

1. Pengukuran in situ Time series menggunakan alat ukur Hobo (Rustam. 2011) untuk memperoleh data primer. Alat ukur ini digunakan untuk memperoleh data oseanografi fisik seperti: elevasi pasang surut, temperatur dan intensitas cahaya. Lokasi pemasangan alat ada di dua pulau dalam gugusan Pulau Pari yaitu pulau Tikus dan Pulau Pari (Gambar 1). Penentuan lokasi berdasarkan hipotesa bahwa pulau-pulau tersebut berada di bagian luar gugusan yang berhadapan langsung dengan laut Jawa tidak ada pemukiman, Data-data primer hasil pengukuran in situ di lapangan ini kemudian di olah menggunakan microsoft excel.

2. Pemodelan hidrodinamika dua dimensi menggunakan pendekatan metoda numerik finite volume (Mustikasari et al., 2015) . Data skunder elevasi pasang surut diperoleh dari model pasut global TMD (the tide model driver) dengan resolusi $1 / 4^{\circ} \times 1 / 4^{\circ}$ berdasarkan 8 komponen pasang surut

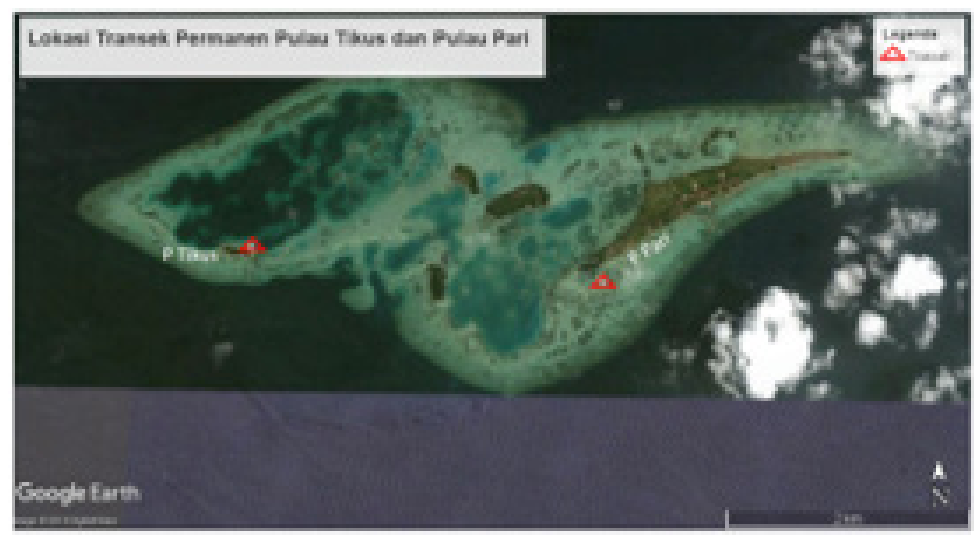

Gambar 1. Lokasi pemasangan Alat Ukur Hobo (sumber: Rustam. 2011)

JURNAL RISET JAKARTA, Vol. 12, No 2, NOVEMBER 2019, Hal. 89-98 
(M2， S2， N2，K2，K1,O1，P1, dan Q1) yang dikembangkan oleh Padman \& Erofeeva (2005), sedangkan pemodelan hidrodinamika di gunakan untuk perhitungan simulasi arus permukaan dua dimensi di wilayah penelitian. Data skunder yang digunakan dalam simulasi pemodelan adalah data batimetri, data garis pantai, dan data pasang surut. Data hasil pengolahan dianalisis secara deskriftif kualitatif dan kuantitatif dalam bentuk grafik/ gambar.

\section{HASIL DAN PEMBAHASAN}

Fenomena fisis dan dinamis air laut di perairan Kepulauan Seribu telah dikaji dan dianalisis dengan hasil sebagai berikut:

\section{Temperatur Dan Intensitas Cahaya}

Temperatur dan intensitas cahaya sangat berpengaruh terhadap laju fotosintesi suatu kawasan. Semakin tinggi Temperatur dan intensitas cahaya, maka fotosintesis akan berlangsung semakin cepat. Besarnya laju fotosintesis dapat diamati dari jumlah $\mathrm{O}_{2}$ yang dihasilkan. Selain kedua faktor di atas, fotosintesis juga dipengaruhi oleh : konsentrasi karbon dioksida, konsentrasi klorofil, air, dan titik kompensasi. Laju fotosintesis juga dikontrol oleh suatu faktor pembatas ketika telah mencapai kondisi maksimum. Gambar 2. Menunjukkan kondisi temperatur dan intensitas cahaya secara umum dikepulauan seribu. Data diperoleh dari hasil perhitungan in situ pada bulan September 2011 menggunakan alat ukur HOBO. Temperatur minimum saat pengamatan berkisar $27,173^{\circ} \mathrm{C}$ dan temperatur maksimum berkisar $33,848^{\circ} \mathrm{C}$, sedangkan intensitas cahaya maksimum mencapai 994,7 Cd.

Gambar 3. menunjukkan bahwa nilai rata-rata temperatur dan intensitas cahaya pada saat pengamatan berbanding lurus, dimana nilai intensitas cahaya meningkat seiring dengan penambahan temperatur. Nilai temperatur rata-rata berkisar antara $28,582^{\circ} \mathrm{C}$ sampai $30,252^{\circ} \mathrm{C}$, sementara nilai intensitas cahaya rata-rata mencapai $0,801 \mathrm{Cd}$ sampai $120,869 \mathrm{Cd}$.

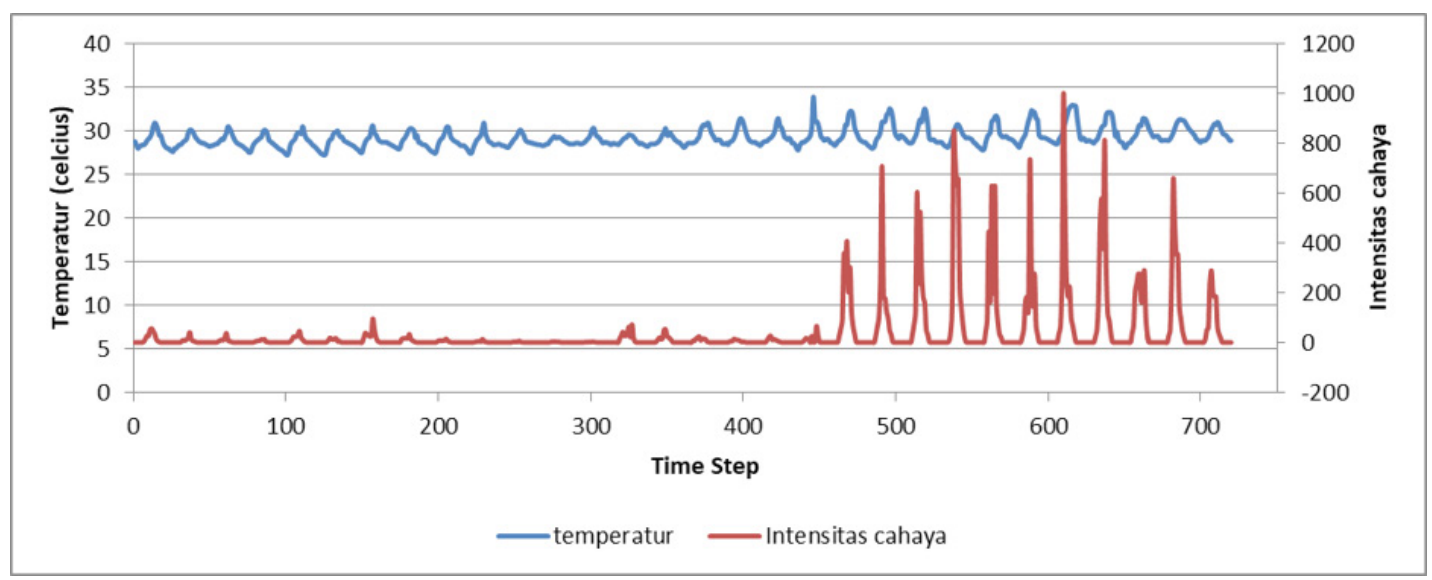

Gambar 2. Temperatur dan Intensitas Cahaya di Kepulawan Seribu.

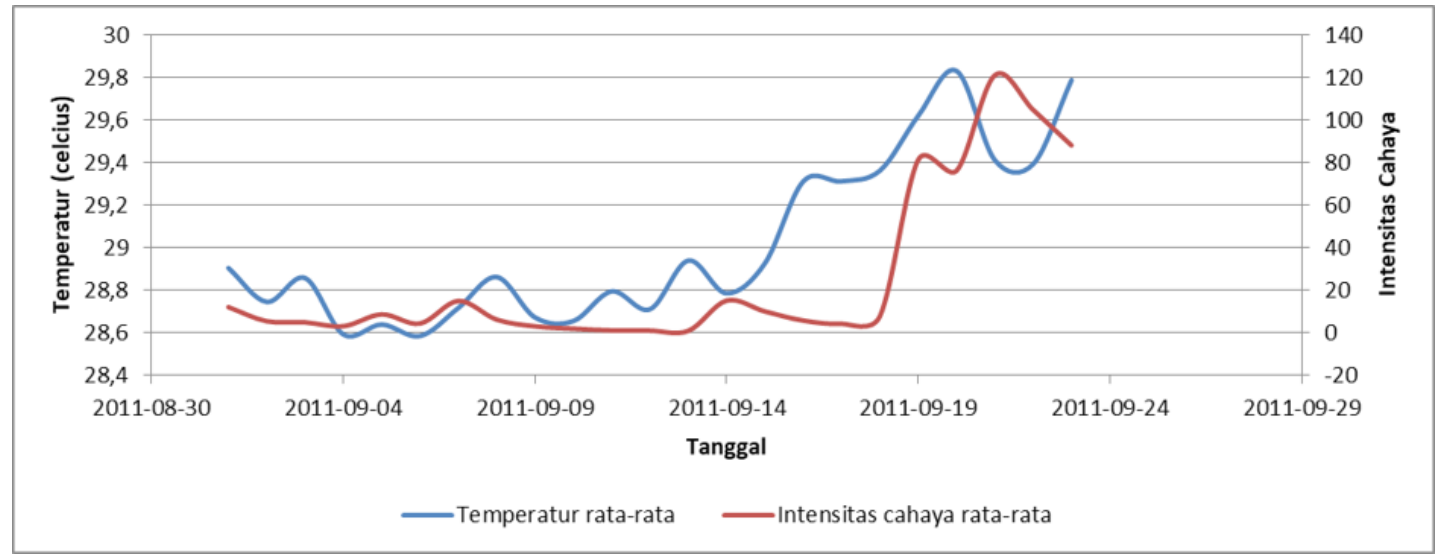

Gambar 3. Nilai Rata-rata Temperatur dan Intensitas Cahaya di Kepulauan Seribu. 
Kondisi suhi terus meningkat, hal ini terjadi karena pada bulan September terjadi peralihan dari musim Timur ke musim Barat. Pulau Pario dan kepulauan seribu lainnya termasuk kedalam wilayah laut Jawa, suhu air Laut Jawa cukup tinggi yaitu di kisaran 27$28^{\circ} \mathrm{C}$ (Widisantosa $\mathrm{H}$ et al. 2016). Wilayah perairan Kepulauan Seribu didominasi oleh ekosistem terumbu karang, padang lamun dan daratan pulau-pulau karang yang menjadi habitat penting berbagai jenis biota perairan laut antara lain terdiri dari berbagai jenis terumbu karang, ikan hias, rumput laut, ganggang laut dan molluska. Kondisi temperatur dan intensitas cahaya di kepulauan seribu menunjukkan bahwa wilayah perairan ini dapat dikategorikan sebagai perairan yang sangat potensial untuk tempat hidup berbagai biota perairan laut yang habitatnya sangat penting itu.

\section{Pasang Surut (Pasut)}

Pasut merupakan salah satu parameter oseanografi yang penting sebagai pembangkit arus di perairan. Tujuan dan kegunaan studi tentang pasang surut terutama adalah untuk kepentingan ilmu (scientific interest); tujuan ini adalah tujuan pertama sekali dari para ilmuwan dalam mempelajari gejala alam. Beberapa aplikasi misalnya dalam navigasi, digunakan untuk memperkirakan tinggi muka air dan kekuatan serta arah arusnya. Type pasut ditentukan oleh frekuensi ari pasang dan surut setiap hari. Tipe pasut ini dihitung edngan mengetahui amplitudo dan periode dari masing-masing komponen. Komponen pasut di Perairan Kepulauan Seribu yang diperoleh dari hasil perhitungan menggunakan model TMD ditunjukkan dalam Tabel 1.

Tipe pasut di perairan Kepulauan Seribu adalah campuran cenderung harian tunggal (mixed mainly diurnal tides) hasil tersebut divisualisasikan pada Gambar 4

Hasil visualisasi didukung oleh hasil perhitungan bilangan Formzal (F) di stasiun penelitian yang berkisar $1.50<\mathrm{F} \leq 3.0$ dengan nilai sebesar 2.109. Sementara Gambar 5. Menunjukkan hasil verifikasi data insitu dengan data hasil simulasi model. Nilai pasut saat pasang tertinggi, pasang terendah, surut terendah dan surut tertinggi seperti di tunjukan pada tabel 2.

Berdasarkan pengukuran insitu di stasiun penelitian bulan September 2011 yang berlokasi di Pulau Pari pada koordinat $05^{\circ} 51^{\prime} 00^{\prime \prime} \mathrm{LS}-106^{\circ} 37^{\prime} 0.12^{\prime \prime} \mathrm{BT}$, kedudukan air tertinggi dan terendah adalah 0,4796

Tabel 1. Tabel Komponen Pasang Surut Di Lokasi P. Pari

\begin{tabular}{llll}
\hline Latitude & Longitude & Parameter & Amplitudo \\
\hline \multirow{2}{*}{5,8500} & \multirow{2}{*}{106,6167} & M2 & 0,0946 \\
& & S2 & 0,0742 \\
& K1 & 0,2588 \\
& O1 & 0,0973 \\
\hline
\end{tabular}

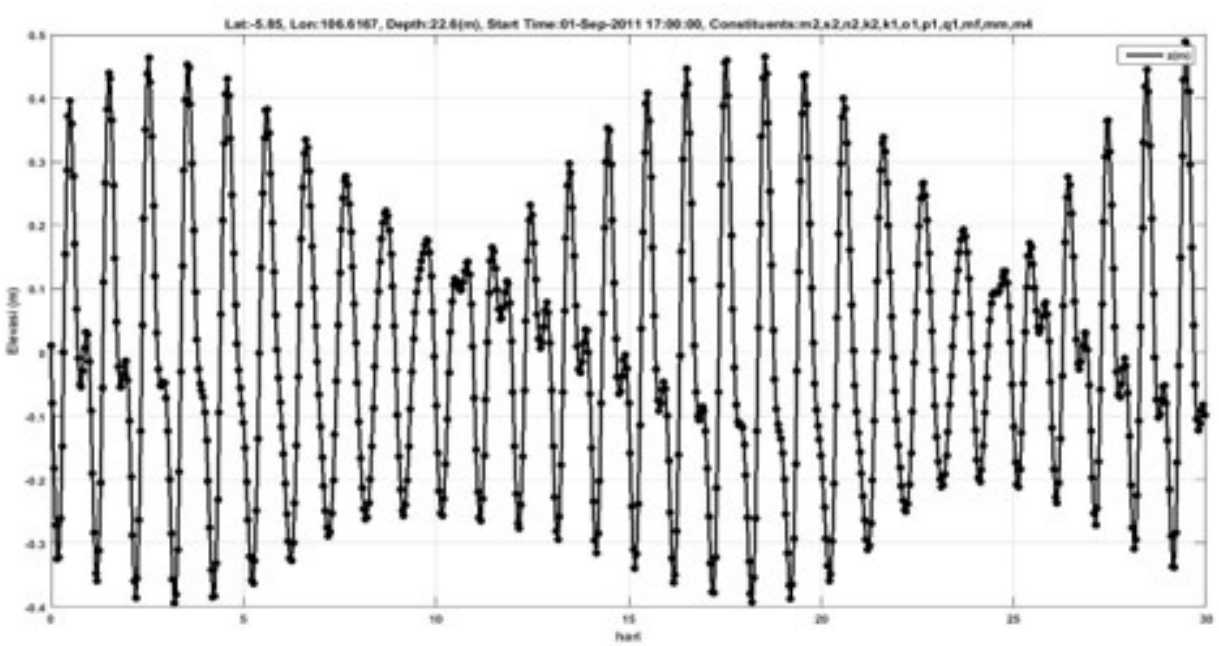

Gambar 4. Visualisasi Pasut di Wilayah pengamatan. 
Tabel 2. Kondisi Pasut

\begin{tabular}{lcll}
\hline Kondisi Pasut & Elevasi (m) & Tanggal & Waktu (Wib) \\
\hline Pasang tertinggi & 0.27564 & 6 September 2011 & 02.00 \\
Surut terendah & -0.33166 & 6 September 2011 & 15.00 \\
Pasang terendah & 0.00221 & 16 September 2011 & 16.00 \\
Surut tertinggi & -0.00049 & 26 September 2011 & 18.00 \\
\hline
\end{tabular}

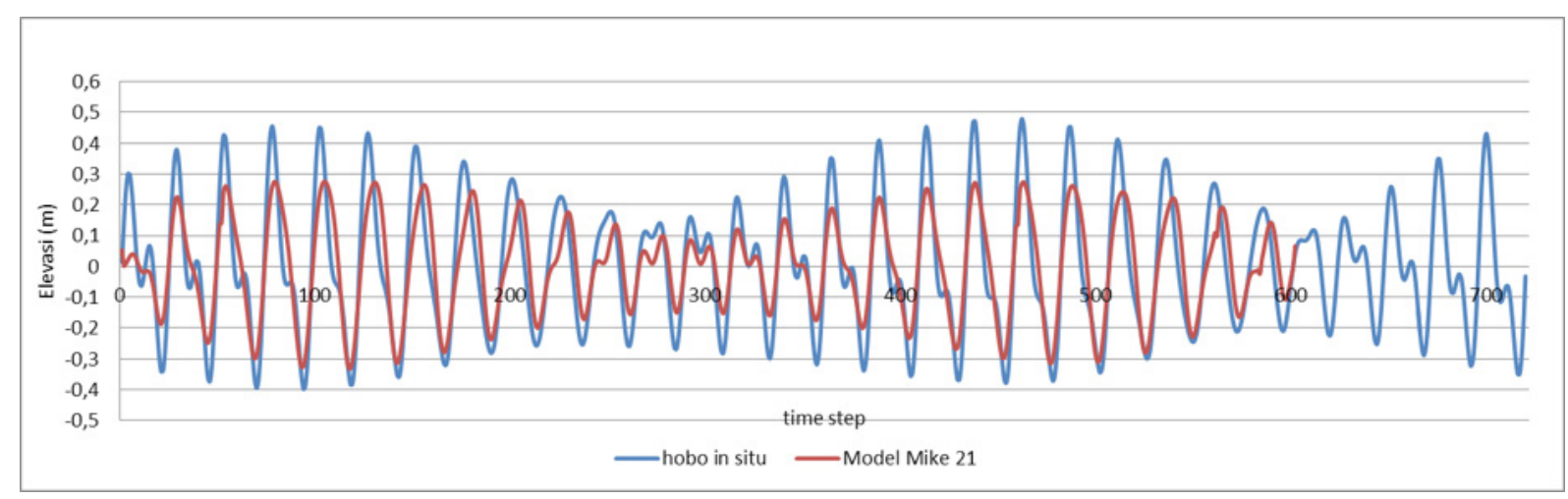

Gambar 5. verifikasi Elevasi muka laut insitu dan hasil model.

dan $-0,3952 \mathrm{~m}$ dari muka laut rata-rata. Sedangkan hasil perhitungan pemodelan menunjukkan bahwa kedudukan pasut tertinggi dan terendah adalah 0,279642 dan $-0,331657 \mathrm{~m}$ dari mula laut rata-rata. Rms error hasil pengukuran elevasi pasut in situ dan perhitungan model menunjukkan nilai 0,01564 . Perbandingan elevasi pasut hasil pengukuran in situ dengan hasil model di tunjukkan pada gambar 3 .

Hasil simulasi model pasut di kepulauan seribu pada saat Purnama dan Perbani ditunjukkan pada Gambar 6. Kajian yang telah dilakukan dibeberapa wilayah ekoregion menunjukkan tipe pasut yang sama (Pranowo et al., 2015).

\section{Arus}

Arus permukaan laut yang disebabkan oleh faktor angin umumnya digerakan oleh stress angin yang bekerja pada permukaan laut. Angin cenderung mendorong lapisan air di permukaan laut dalam arah gerakan angin (M Azis F, 2006). Arus yang di ukur dalam penelitian ini adalah Arus yang disebabkan oleh faktor eksternal yaitu gaya tarik menarik antara bumi dan benda benda angkasa yang disebut dengan arus pasang surut (Pasut). Arus pasut ini merupakan arus yang gerakannya horizontal atau dikenal dengan arus barotropik 2 Dimensi (2D) dimana densitas perairan hanya fungsi dari tekanan. Didalam aliran barotropik angin thermal tidak ada, maka aliran pada semua level dianggap sama dan tidak ada vertical wind shear di aliran barotropik.
Simulasi arus dalam penelitian ini dilakukan selama rentang waktu 30 hari pada bulan September 2011. Gambar 7 menunjukan besaran kecepatan arus arah $\mathrm{u}$ dan $\mathrm{v}$ di wilayah penelitian sementara Gambar 8 menunjukkan resultan kecepatan arus dari kedua vektor tersebut. Menurut Pond \& Pickard, 1983: Gerakan massa air atau arus terjadi karena resultan dari berbagai macam gaya yang bekerja pada kolom massa air yang memiliki suatu percepatan (Siregar et al., 2015), namun dalam penelitian ini kolom air dan kedalaman belum diperhitungkan, pergerakan arus hanya dipengaruhi oleh gaya yang bekerja pada permukaan yang digerakkan oleh pasut.

Hasil simulasi model arus di Kepulauan Seribu divisualisasikan pada Gambar 9. Dari hasil simulasi diperoleh perhitungan nilai kecepatan arus maksimum pada bulan September 2011 berkisar 0,164 m/det. sedangkan kecepatan arus minimum berkisar $0,002 \mathrm{~m} /$ det. Kecepatan arus ini akan berkurang cepat sesuai dengan makin bertambahnya kedalaman perairan dan akhirnya angin tidak berpengaruh sama sekali terhadap kecepatan arus pada kedalaman 200m Perubahan pergerakan arah arus yang kompleks salah satunya disebabkan oleh adanya gaya Coriolis Pada saat kecepatan arus berkurang, maka tingkat perubahan arah arus yang disebabkan oleh gaya Coriolis akan meningkat. Hasilnya akan dihasilkan sedikit pembelokan dari arah arus yang relatif cepat di lapisan permukaan. 

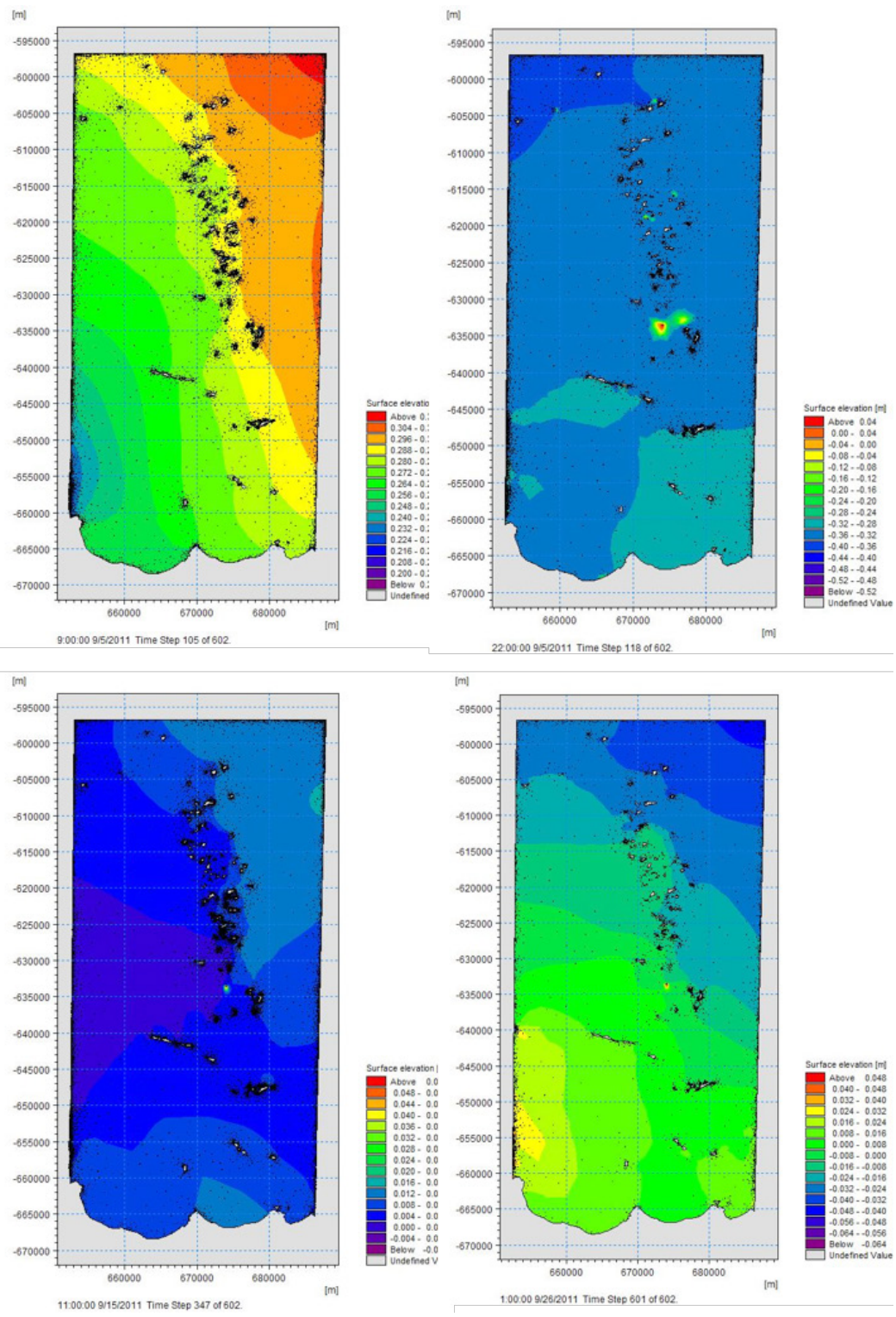

Gambar 6. verifikasi Elevasi muka laut insitu dan hasil model.

Kecepatan arus saat menuju pasang (u) Ke cepatan arus saat menuju surut (u). Kecepatan arus saat menuju pasang (v) Kecepatan arus saat menuju surut (v)
Arus yang dibangkitkan oleh pasut dipengaruhi oleh dasar perairan. Arus pasut yang terkuat akan ditemui di dekat permukaan dan akan menurun kecepatannya semakin mendekat dasar perairan. Hal ini disebabkan

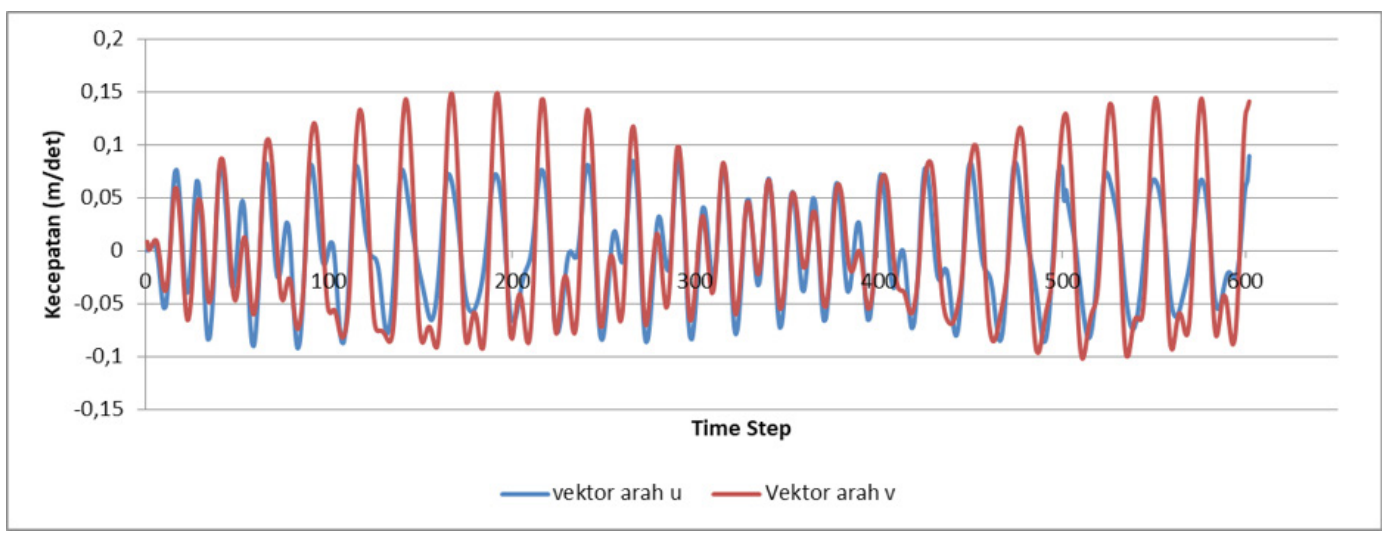

Gambar 7. Besaran kecepatan arus arah u dan v. 


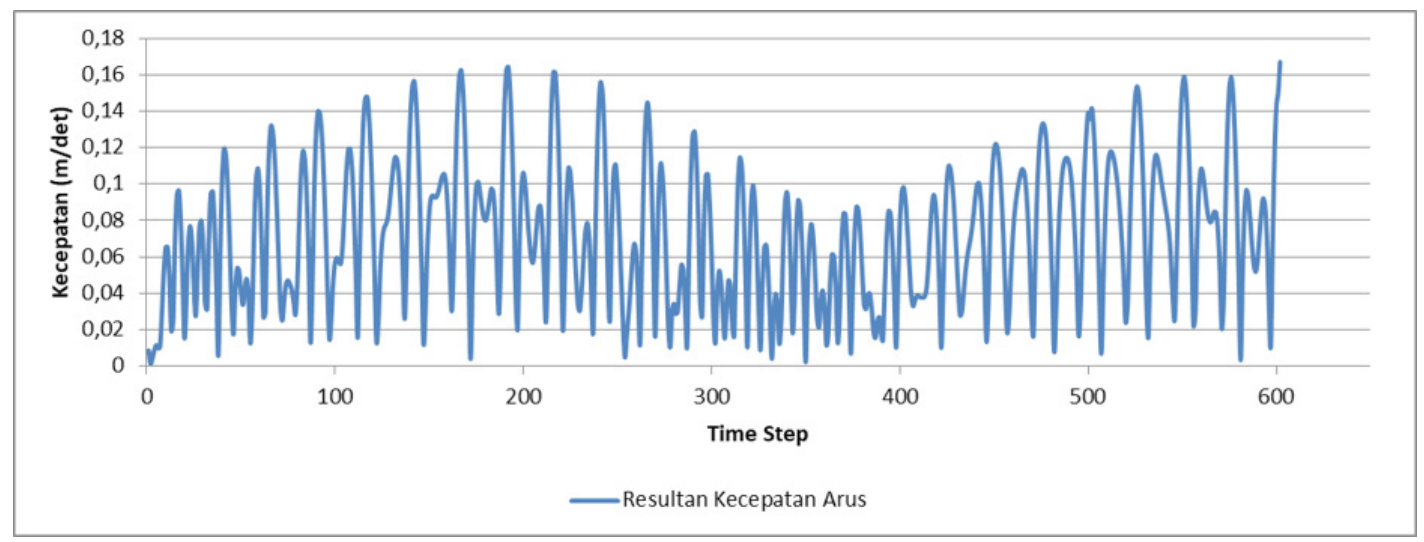

Gambar 8. Resultan kecepatan arus arah u dan v.

adanya gesekan dasar (Bottom Friction). Simulasi model dalam penelitian ini belum memasukkan unsur angin sebagai gaya pembangkit arus. Konfigurasi topografi dasar laut, waktu pasang-surut, kondisi
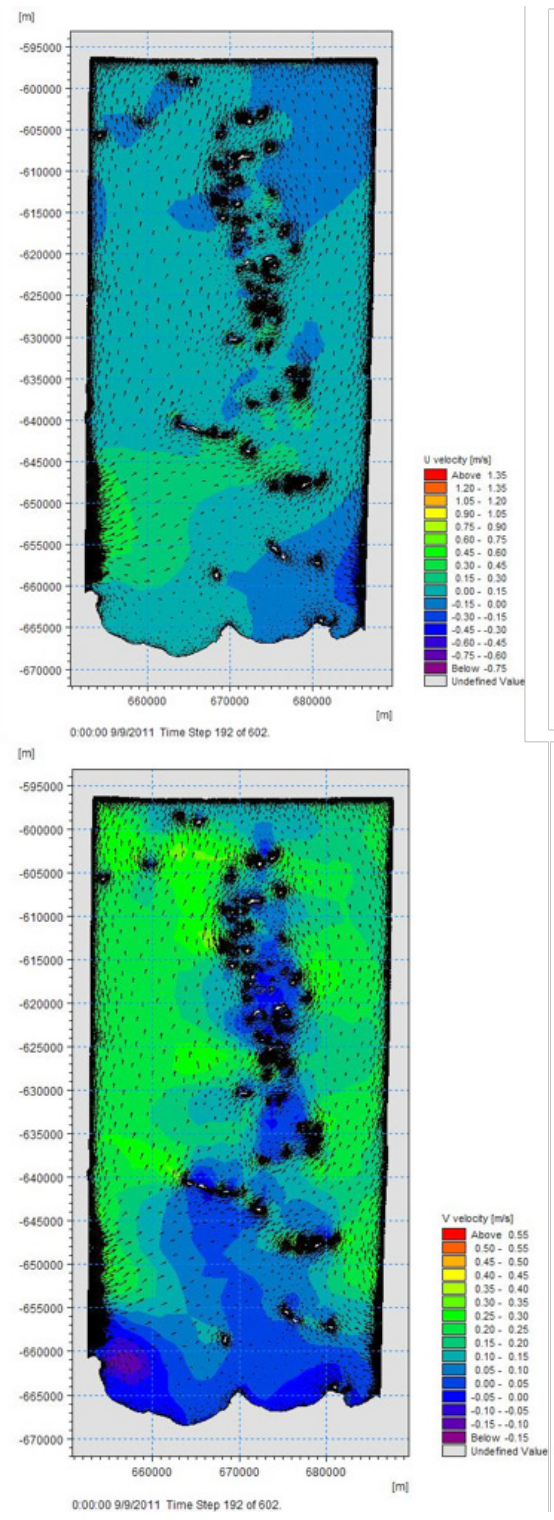

cuaca musiman dan posisi kepulauan terhadap lautlaut luas di sekitarnya memberikan terjadinya berbagai variasi perubahan-perubahan arah dan kecepatan arus dalam satuan-satuan waktu tertentu dalam sehari. Hal
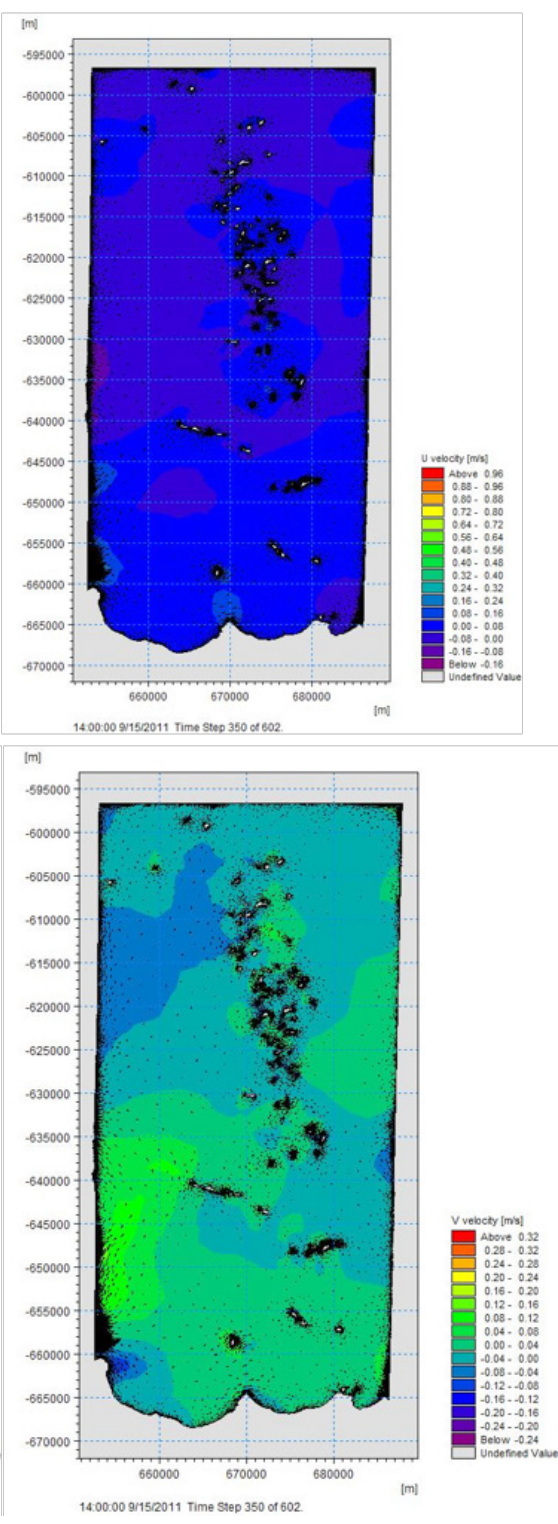

Gambar 9. Simulasi vektor arus (u dan v) saat menuju pasang dan saat menuju surut .

Karakteristik Fisis Air Laut dan Dinamika Perairan Kepulauan Seribu - Eva Mustikasari, Agustin Rustam, Hadi Lesmana Salim, Dwi Yoga Nugroho, Aida Heriati \& Utami R. Kadarwati 
inilah yang menyebabkan dinamika laju sedimen dan keanekaragaman ekosistem mangrove menjadi lebih dinamis.

\section{KESIMPULAN DAN SARAN}

\section{Kesimpulan}

Hasil simulasi numerik menunjukkan Fenomena fisis dan dinamika perairan Kepulauan Seribu adalah sebagai berikut :

- Temperatur rata-rata perairan di Kepulauan seribu mencapai $28,582^{\circ} \mathrm{C}$ sampai $30,252^{\circ} \mathrm{C}$, sementara nilai intensitas cahaya rata-rata mencapai $0,801 \mathrm{Cd}$ sampai 120,869 Cd. Merupakan wilayah perairan yang subur dan potensial untuk tumbuh kembang aneka ragam hayati laut.

- Tipe pasang surut di Kepulauan Seribu merupakan tipe pasang surut Campuran condong harian tunggal dengan nilai bilangan Formzal sebesar 2,109 .

- Pasang surut maksimum dan minimum dari data hasil pengukuran insitu adalah 0,4796 dan -0.3952 m dari muka laut rata-rata. Sedangkan hasil simulasi numerik pasang surut tertinggi dan terendah adalah 0,279642 dan $-0,331657 \mathrm{~m}$ dari mula laut rata-rata. Rms error hasil pengukuran elevasi pasut in situ dan simulasi numerik menunjukkan nilai 0,01564.

- Kecepatan arus maksimum 0,164 m/det. sedangkan kecepatan arus minimum berkisar $0,002 \mathrm{~m} /$ det.

\section{Saran}

Simulasi numerik sebaiknya tidak hanya melihat kondisi permukaan saja, tetapi harus melihat juga kondisi kedalaman perairan. Agar terlihat kondisi di musim yang berbeda, mana simulasi numerik sebaiknya memasukkan unsur angin dalam proses perhitungannya.

\section{UCAPAN TERIMA KASIH}

Ucapan mbantu terlaksananya seluruh kegiatan penelitian sampai selesai.

\section{DAFTAR PUSTAKA}

Suhendar I Sachoemar., 2008. Karakteristik Lingkungan Perairan Kepulauan Seribu, Badan Pengkajian dan Penerapan Teknologi. JAI, 4(2).

Dahuri. Dr, Rais J. Prof., Ginting S.Ir.,Sitepu. M.J.Dr., (2013). Pengelolaan Sumber Daya Wilayah Pesisir dan Lautan Secara Terpadu, Balai
Pustaka, Buku.

Pranowo, W. S., T. Arifin, \& A. Heriati. (2014). Sirkulasi Arus Perairan Teluk Jakarta Pra dan Pasca-Konstruksi Jakarta Giant Sea Wall. Book Chapter in "Dinamika Teluk Jakarta: Analisis Prediksi Dampak Pembangunan Tanggul Laut Jakarta (Jakarta Giant Sea Wall)". Poernomo, A., B. Sulistiyo, S. Wirasantosa, I.S. Brodjonegoro (Eds). IPB Press, ISBN: 978-979-493-776-1. Page: 57-68.

Arifin, T., \& Mustikasari E. (2014). Kondisi Pasang Surut, Arus dan Gelombang di Teluk Jakarta. Book Chapter in "Dinamika Teluk Jakarta: Analisis Prediksi Dampak Pembangunan Tanggul Laut Jakarta (Jakarta Giant Sea Wall)". Poernomo, A., B. Sulistiyo, S. Wirasantosa, I.S. Brodjonegoro (Eds). IPB Press, ISBN: 978-979493-776-1. Page: 27-41.

Mustikasari, E., Dewi, L.C., Heriati, A., \& Pranowo W.S. (2015). Pemodelan Pola Arus Barotropik Musiman 3 Dimensi(3D) Untuk Mensimulasikan Fenomena Up Welling Di Perairan Indonesia. Jurnal Segara. 11(1), 25-35.

Widisantosa, H., Pranowo, W.S., Simanjutak, S.M., \& Setiadi, H. (2016). Studi Konstanta Harmonik Pasang Surut Terhadap Data Suhu Permukaan Laut di Perairan Pulau Pari. J. Chart Datum. 2 (2): 32-43.

Siregar, S.N., L.P. Sari, N.P. Purba, W.S. Pranowo, \& M.L. Syamsuddin. (2017). Pertukaran massa air di Laut Jawa terhadap periodisitas monsun dan Arlindo pada tahun 2015. J. Depik. 6(1): 44-59. DOI: 10.13170/depik.6.1.5523.

Pranowo, W.S., G. Pramono, M. Hutomo, A. Nontji, \& I. Maufikoh. (2014). Karakteristik Oseanografi Ekoregion Laut Provinsi DKI Jakarta. Book Chapter in "Dinamika Teluk Jakarta: Analisis Prediksi Dampak Pembangunan Tanggul Laut Jakarta (Jakarta Giant Sea Wall) ". Poernomo, A., B. Sulistiyo, S. Wirasantosa, I.S. Brodjonegoro (Eds). IPB Press, ISBN: 978-979-493-776-1. Page: 43-56.

Rustam, A. (2019). Pemantauan Ekosistem Lamun Pulau Pari dan Pulau Tikus, inpress.

M. Azis F. (2006). Gerak Air Laut. Oseana, 31(4), 9 
- 21. sumber:www.oseanografi.lipi.go.id. ISSN: 0216-1877.

Anonymous. (2016). Keadaan umum wilayah kepulauan seribu, http://ancol-pulauseribu.com/ keadaan-umum-wilayah-kepulauan-seribu/, diunduh pada tanggal 5 september 2019 jam 09.55 wib.

Anonymous. (2019). Kepulauan seribu, http://eecn. or.id/sejarah-kepulauan-seribu/ copyright EECN2019. diunduh pada tanggal 5 september jam 09.55 wib

Anonymous. (2019). https://www.academia. edu/5461513/LAPORAN_OSEFIS 
